\title{
Does Group Re-Group Strategies Impact on Students' Texts Interpretation?
}

\author{
Graceful Onovughe Ofodu \\ Institute of Education, Faculty of Education, Ekiti State University, Ado-Ekiti, Nigeria
}

\begin{abstract}
The main pursuit of the present paper is to examine the impact of group re-group strategies on students' texts interpretation. The focus of this study is on the use of two cooperative strategies in empowering learners to become effective readers.

Using a pretest and posttest control group design through the reading comprehension test, the researcher tested the effect of the group re-group strategies on learners' ability to interpret texts. The result showed that there was significant impact of the Reciprocal Teaching Strategies (RTS) on students' text processing than the Think-Pair -Share Strategy and the conventional method of teaching reading in schools. The impact of the RTS was also noticed on students' level of interpretation which was closely followed by the TPSS. None of the strategy impacted on male or female students' text interpretation.
\end{abstract}

\section{Introduction}

Living in the twenty first century requires the use of the right strategy for maximum processing of information. Learning within and outside the classroom involves the consumption of a lot of information and interpretation of what is spoken, read and written. A learner's ability to interpret what is read holds great significance to his academic achievement within the school system because much of what he is required to do will revolve around reading and comprehension. Reading comprehension is a complex cognitive process that involves both lower (decoding, orthographic processes) and higher level processing of information to extract meaning from text.

Research evidence has proved that many students still have problem reading and interpreting academic materials Ofodu [8]; Muodumogu [7]; Ofodu \& Lawal [10], Ofodu \& Adedipe [9]. Other researchers have also found that the use of texts in science classrooms has waned significantly over the past two decades because expository texts have fared poorly as vehicles for promoting comprehension, learning and conceptual Sinatra \& Broughton [18]. Many reasons have been advanced for this disturbing phenomenon and trend. Prominent among them is the poor teaching strategies and methods employed in teaching reading. Isuigo-Abanihe [2] in her evaluative study in one of the states in Nigeria discovered that reading educators teach reading as individual affair in which the learner logs to the textbook with no room for interaction with peers groups. Supporting this finding, Jegede, Onukaogu, Arua and Inyang [3] lamented that discussion as a method of teaching reading is never mentioned in many English textbooks, syllabuses and teachers' manual.

Despite extensive research efforts Ayodele [1]; Oladunjoye [12]; Kolawole [4] at correcting this anomaly, surprisingly within the Nigerian context no empirical studies have been conducted using the Group Re-group Strategies in order to see how it might impact on students' text interpretation. There is therefore the need to fill this gap.

Group Re-group Strategies are the cooperative instructional strategies where students work together to construct knowledge for themselves instead of waiting passively for teachers to read and interpret texts meaning. Since meaning is central to language learning, it is very essential that students learn from their mates who have known some good strategies for constructing meaning. Pairs of students work together representing the most effective form of interaction, followed by threesome and larger groups Schwartz, Black \& Strange [17]. The two types of Group Regroup strategies employed are Reciprocal Teaching and Think-Pair Share. The first strategy involve students working in pairs, all students are involved in the reading process after which, they are paired with one of their mates who might be a good or average reader and they are allowed to share what they have comprehended from the text. Both the speaker and the listener develop valuable problem solving skills by formulating their ideas, discussing them, receiving immediate feedback and responding to questions and comments by their partner. The second strategy is called reciprocal teaching. This strategy involves the use of four strategies: predicting, clarifying, summarizing and questioning. There is room for exchange of roles and regrouping of the learner for effective understanding Ofodu \& Lawal, 2010b [11]. 
The benefits of group dialogue or discussion have been well documented in literature Woolfolk [20]; Manak 2011[5]. Students are directly involved and participatory learning is greatly enhanced. Learners express themselves clearly, justify their opinions and tolerate different and new ideas. They clarify, examine their own thinking, follow personal interests and assume responsibility by taking leadership roles in the group. These group discussions help students evaluate ideas and synthesize personal viewpoints. Discussions are also useful when students are trying to understand difficult concepts that go against common sense.

The concept of Group Re-Group strategy is not new in language learning. Oladunjoye [12] states that this strategy allows opportunity for integrated language and content instruction which in turn offers a means by which English as Second Language (ESL) students can continue acquiring academic language proficiency. The social setting of Group Re-Group provides the opportunity where students' discussion improves recall of text content. When students read a text together and explain the concepts to one another they engage in higher order learning.

Oyeneye [14] asserts that children learn to read, write and improve their mathematics skills when they work in groups cooperatively. Commenting on the benefits of group work, she adds that children develop the spirit of team work and appreciate the uniqueness of one another as they coordinate themselves and assume leadership roles. Corroborating this Palincsar [19] and Woolfolk [20] assert that students learn more when they engage in talks that are interpretative, analytical and explanatory because talking enhances recall and comprehension of materials.

Woolfolk [20] explains that skilled readers apply almost automatically some skills and strategies whenever they process print but poor readers seldom do probably because they do not know how to use them. Onukaogu [13] points out that the inferential comprehension of many students is enhanced during the thinking process as they draw from their previous experiences and these experiences assist them to interpret the purpose, tone or mood that informed the experience which a writer is conveying in his text. He added that unless teachers empower pupils to read extensively and make efforts to dialogue what they have read, learners may never be able to make valid inferences.

In the light of these premises, the purposes of the present study were to: (a) ascertain the general performance of students in reading comprehension before and after the treatment? (b) find which of the two methods (TPSM and RTM) is more effective in teaching reading comprehension at literal, inferential and critical levels? (c) Determine the effect of these strategies on male and female students before and after treatment. Guiding questions for this study included the following:

- What is the general performance of students in reading comprehension before and after the treatment?

- Which of the two strategies (TPSS and RTS) is more effective in teaching reading comprehension at literal, inferential and critical levels?

- Which of the two strategies will impact more on male and female students?

\section{Methods}

Using a pretest and posttest control group design through the reading comprehension test, the researcher tested the effect of the group re-group strategies on learners' ability to interpret texts. Stratified sampling technique was used to select 144 secondary school students from three secondary schools in Ado-Ekiti, Aramoko-Ekiti and Ikere-Ekiti Local Government Areas. Ninety (96) students were sampled for the experimental groups and forty-eight (48) students were sampled for the control group. Two main researcher-designed instruments were used for the study. First was the Cooperative Instructional Guide for Teachers made up of two sets of guides for teaching the two experimental groups. The second was the Reading Comprehension Test (RCT) made up of a three-passage comprehension achievement test. The RCT was used to streamline students into three main performance levels: low performance, average performance and high performance. Reliability index was determined through a test-retest procedure of two weeks interval. Reliability coefficient of 0.88 and 0.90 were obtained using Pearson Product Moment Correlation Coefficient and Guttman's Split-half statistics respectively. Analysis of data was done by computing the mean scores bar charts.

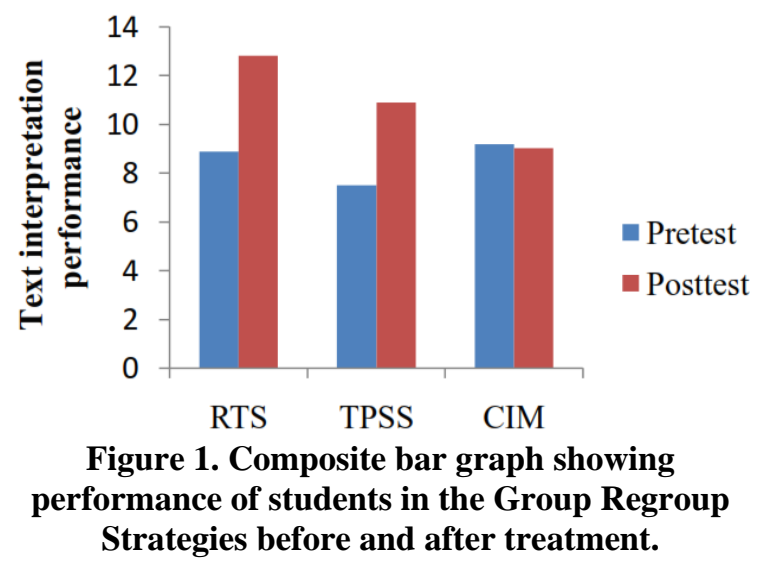




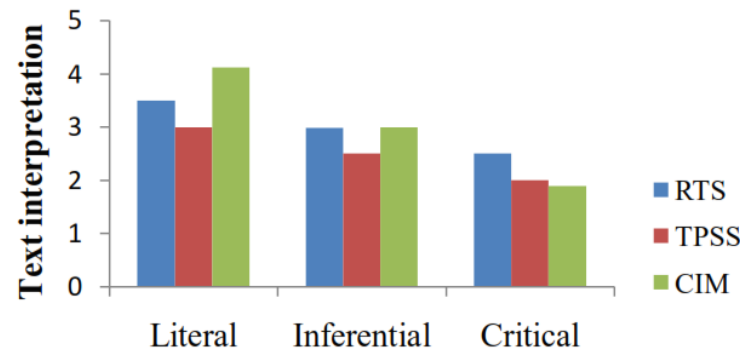

Figure 2. Composite bar graph showing Group Regroup Strategies and levels of interpretation before treatment.

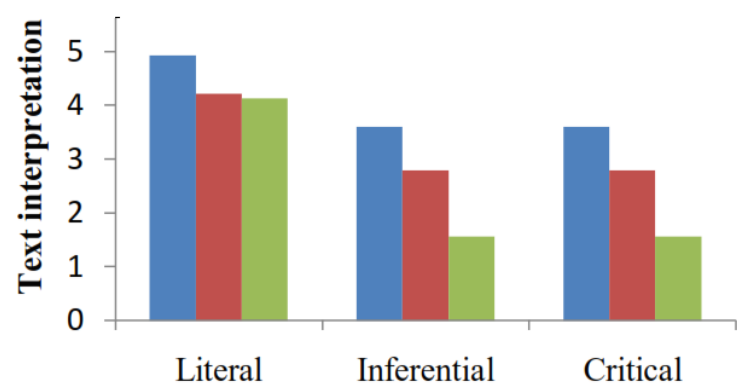

Figure 3. A composite bar chart showing performance in Group Regroup Strategies and levels of interpretation after treatment.

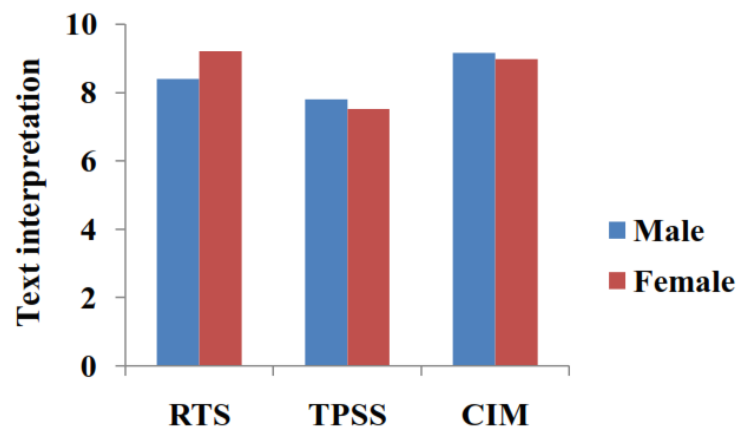

Figure 4. A composite bar chart showing pretest mean scores of male and female students in Group Regroup Strategies.

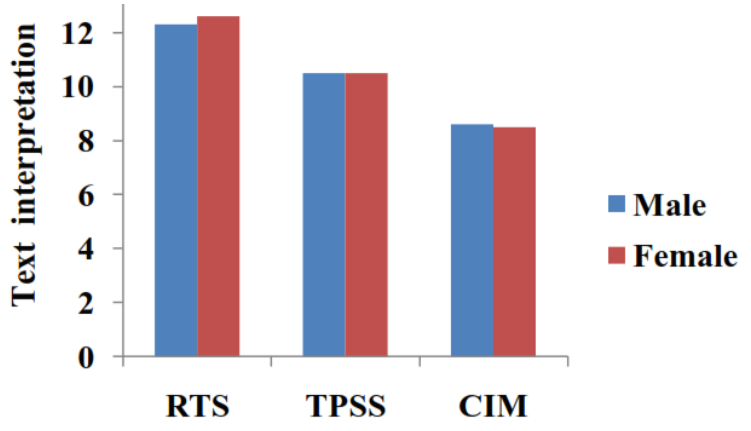

Figure 5. shows the posttest mean scores of the three groups after treatment.

\section{Results}

Figure 1 reveals the mean scores for the RTS, TPSS and CIM groups before and after treatment. It reveals the difference between the pretest means scores and posttest mean scores. For RTS, the pretest mean score was 8.88 while the post test score was 12.81, TPSS pretest score was 7.50 while the post test score was 10.90 and the CIM pretest mean score was 9.19 while the post test score was 9.02.

Figure 2 is a composite bar graph of the mean scores of the three groups before treatment. At the literal level, the RTS group had a mean score $(\mathrm{x}=$ 3.5), TPSS $(x=3.00)$, CIM (4.12) while at the inferential, RTS group had $(x=2.99)$, TPSS $(x=2.5)$ and CIM ( $\mathrm{x}=3.00)$ and at the critical level, RTS ( $\mathrm{x}=$ $2.50)$, TPSS $(x=2.00)$ and CIM $(x=1.89)$

Figure 3 represents the post-test mean scores of the three groups after treatment. At the literal level, RTS group had a mean score of $(\mathrm{x}=4.92)$, TPSS ( $\mathrm{x}$ $=4.21)$ and CIM $(x=4.13)$. At the inferential level, RTS $(x=3.60)$, TPSS $(x=2.79)$ and CIM $(x=1.56)$, while at the critical level, RTS $(x=3.60)$, TPSS $(x=$ 2.79) and CIM ( $\mathrm{x}=1.56)$.

Figure 4 and 5 show the posttest mean scores of the three groups, that is, RTS, TPSS, CIM before and after treatment. There is little or no difference between the pretest and the posttest mean scores.

The result revealed that the RTS group had the higher mean score, showing that the students performed significantly better than TPSS group. Oyeneye [14] corroborates this by asserting that children learn to read, write and improve their mathematics skills when they work in groups cooperatively. Commenting on the benefits of group work, she adds that children develop the spirit of team work and appreciate the uniqueness of one another as they coordinate themselves and assume leadership roles. One more important reason for the enhanced performance of RTS group is that all members of the group had the opportunity to take part in the reading process, especially the quiet and shy ones who are often neglected in traditional reading classes Isuigo- Abanihe [2].

The result indicated that closely following the RTS group was the TPSS group as students in this group outperformed students in the Conventional Instructional Method (CIM) group. As pointed out by Jegede, et al [3], reading should elicit dialogues. The use of dialogues, according to them, is inevitable reflections of successful and purposeful social contexts. They suggested that pupils need to share and discuss what they read, what they have read, and what they want to read. This may have influenced the performance of the students in these groups since they had dialogues in pairs and had ample opportunities to help each other understand the prints. In the CIM group, treatment of new words dominated reading lessons. Teachers more often than 
the learners talked about the text, either by telling the story of the text or explaining unfamiliar grammatical structures Isuigo Abanihe [2]

Based on these submissions, it can be inferred that the two cooperative instructional strategies are effective instructional strategies of teaching reading comprehension in schools, although the RTS is superior to the TPSS.

The study revealed that there were significant effects of the two instructional strategies on students' comprehension levels. But, the RTS had the greater impact on students' literal, inferential and critical levels of comprehension. This finding is consistent with research findings on the usefulness of the RTS.

Closely following the RTS was the effect of the TPSS on students' comprehension at literal, inferential and critical levels. Slavin and Tanner [19] cited in Oladunjoye [12] assert that cooperative discussions improve students' recall of text content. When students read a text together and explain the concepts to each other and evaluate each other's explanation, they engage in critical thinking and inferencing skills. Woolfolk [20] suggests that teachers should develop students' thinking, by creating a culture of thinking in their classrooms, that is, the spirit of inquisitiveness and critical thinking and encourage practice in thinking through interactions with others. Palincsar [16] adds that students surrounded by a rich language of thinking are more likely to think deeply about anything. He adds that students learn more when they engage in talks that are interpretative, analytical and explanatory.

It was gathered from the findings that there was no difference between the performance of male and female students exposed to Think-Pair-Share strategies and those in the Conventional Instructional Method. One would have expected that this method would enhance the performance of the females better than that of males as it involves talking since it is generally believed that females talk more than males. The result indicated no significant difference in the reading performance of students based on gender. Like the TPSS, the RTS encouraged active participation of students and use of techniques that could have enhanced the performance of male and female students differently, but the findings show no difference.

This is not a surprise as none of these cooperative methods is specifically inclined to influence learning for a particular sex. This finding is in agreement with Oladunjoye [12] observes that there was significant difference between male and female students achievement in verbal communication. Thus, the nonsignificant interaction between method and gender suggests that the RTS, as the case of TPSS, is consistent for both male and female students with the same measure of instructional advantage.

\section{References}

[1] Ayodele, S. O. (2001). The use of English in educating Nigerian youths: From the problem to the solution. An Inaugural Lecture. University of Ibadan.

[2] Isiugo-Abanihe, I.M. (2002). "Qualitative evaluation of reading instruction in Abia State”. In A. Lawal, I. IsiugoAbanihe \& I.N. Ohia (Eds.) Perspectives on Applied Linguistics in Language and literature. Ibadan: StirlingHorden Publishers.

[3] Jegede, O.B., Onukaogu C.E., Arua, A.E. \& Iyang, S. (2003). "Some strategies for comprehending the reading text”. In C.E. Onukaogu, A.E. Arua \& O.B. Jegede (Eds) Teaching Reading in Nigeria: A guidebook to Theory and Practice. Ibadan: International Reading Association.

[4] Kolawole, C.O.O. \& Ajayi H .O. (2004). "Home psychosocial environment as correlates of children's reading proficiency". Journal of Early childhood Association of Nigeria (JECAN) 1, 2 109-117.

[5] Manak, Jennifer (2011). "The social construction of intertextuality and literary understanding: The impact of interactive read-alouds and writing of third graders during writing workshops”. Reading Research Quarterly 46.4, 309-311.

[6] McNamara, D.S.\& Magliano, J.P.(2009). "Towards a comprehension model of comprehension”. In B. Ross (Ed.), The psychology of learning and motivation 297-383. Oxford, United Kingdom: Elsevier.

[7] Muodumogu, A.C. (2009). "An evaluation of Benue State university students' awareness and application of metacognitive strategies to reading”. Literacy and Reading in Nigeria, 12, No.1.

[8] Ofodu, G.O. (2009). Comparative effects of two cooperative instructional methods on reading performance of secondary school students in Ekiti State, Nigeria. An Unpublished Ph.D Dissertation, University of Ilorin, Ilorin.

[9] Ofodu, G.O.\& Adedipe, T.H. (2011). “Assessing ESL students' awareness and application of metacognitive strategies in comprehending academic materials”. Journal of Emerging Trends in Educational Research and Policy Studies (JETERAPS) 2(5):343-346.

[10] Ofodu, G.O. \& Lawal, R. A. (2010a). "Moving students beyond the literal level of comprehension: The reciprocal teaching and think-pair share strategies”. In D.D.Kuupole \& I. Bariki (Eds) Applied Social Dimensions of Language Use and Teaching in West Africa 216-223.

[11] Ofodu, G.O.\&Lawal, R.A.(2010b). "Learning strategy, gender and performance levels of secondary school students in comprehension”. International Journal of Research in Counselling and Sports Sciences 1.1. 19-27.

[12] Oladunjoye, O.O. (2003). "Learning strategy, gender and achievement in verbal communication in the English language”. Ibadan Journal of Educational Studies 3, 1115. 
[13] Onukaogu, C.E. (2003). "Towards the understanding of reading”. In C.E. Onukaogu., A.E. Arua \& O.B. Jegede (Eds) Teaching reading in Nigeria: A guidebook to theory and practice. Ibadan: International Reading Association.

[14] Oyeneye, S. (1999). "The role of group work in Mathematics”. In O.T.Oyetunde., T.O. Akinmade \& G.O. Akpa (Eds.) Primary Methods Jos: Conference on Education Improvement.

[15] Oyetunde, T. (2002). "How do secondary school students process print?” In A. Lawal., I. Isugo-Abanihe \& I.N. Ohia (Eds.) Perspectives on Applied Linguistics in Language and Literature. Ibadan: Stirling Horden Publishers.

[16] Palinscar, A.S. (1998). "Reciprocal teaching and questioning”. In A. Woolfolk, Educational Psychology India: Pearson Books.

[17] Schwartz, D.L.,Black, J.B. \& Strange, J.(1991). "Dyads have four advantage over individuals inducing abstract rules". Paper presented at the annual meeting of the America Educational Research Association, Chicago.

[18] Sinatra, G.M. \& Broughton, S.H.(2011). Bridging reading comprehension and conceptual change in science education: The promise of refutation text.

[19] Slavin, R.E. \& Tanner, A.M. (1979). "Effects of cooperative reward structures and individual accountability in productivity and learning". Journal of Educational Research 72, 5. 294-298 Research Quarterly. 46(4)374393.

[20] Woolfolk, A (2006). Educational Psychology (9th Ed) India: Pearson Education. 